\title{
Rehabilitation of People with Lower-Limb Amputations
}

\author{
Goeran Fiedler · Jonathan Akins · Rosemarie Cooper • \\ Santiago Munoz $\cdot$ Rory A. Cooper
}

Published online: 21 September 2014

(C) Springer Science+Business Media New York (Outside the USA) 2014

\begin{abstract}
Rehabilitation of persons with lower-limb amputation is a complex endeavor that requires the consideration of a multitude of factors. This article provides an overview of the current practice of prosthesis prescription, mobility training, and the utilization of wheeled mobility options in the clinical care for this population. Recent technological advancements have helped fit persons with lower-limb amputation with more functional, better fitting, and less activity-limiting artificial limbs and wheelchairs. This is exemplified in modern computer-controlled prosthetic components and biomechanically optimized socketfitting methods, as well as light weight and versatile wheelchairs to supplement or replace prosthetic devices. In the research setting, technology has enabled new approaches to the kinematic and kinetic assessment of prosthetic interventions, and the development of more accurate fitting and evaluation methods. Despite the noted progress in the field, there is still a considerable gap between the functionality of a sound leg and even the most advanced prosthesis. It can be predicted that continued research efforts will be undertaken to further close this gap.
\end{abstract}

G. Fiedler · J. Akins - R. Cooper - S. Munoz $\cdot$ R. A. Cooper Department of Rehabilitation Science \& Technology, University of Pittsburgh, Pittsburgh, PA 15260, USA

R. Cooper

UPMC Health System Center for Assistive Technology, Pittsburgh, PA 15260, USA

\section{R. A. Cooper $(\bowtie)$}

Human Engineering Research Laboratories, U.S. Department of Veterans Affairs, 6425 Penn Avenue, Suite 400, Pittsburgh, PA 15206, USA

e-mail: rcooper@pitt.edu
Keywords Artificial limb - Biomechanics - Gait analysis · Lower-limb amputation · Rehabilitation · Wheelchair

\section{Introduction}

Between amputations and congenital deficiencies as mechanism of lower-limb loss, amputations are by far most prevalent, representing more than $99 \%$ of all cases in the US [1]. In the population of under 15 year olds, congenital defects represent the majority of limb loss cases [2], as the accumulated risk for amputation is comparably low [3, 4]. The incidence of the major causes for amputation, namely traumata, tumors, and most of all, vascular diseases, increases with the time at risk and as a direct result of physical aging [5-7]. Currently, more than $80 \%$ of amputations in the United States are secondary to dysvascular disease, with an equal division between peripheral vascular disease and diabetes. Less than $10 \%$ result from trauma [8].

Rehabilitation of persons with lower-limb amputation poses, therefore, generally slightly different challenges than the rehabilitation of persons with congenital limb loss. Members of the latter population begin coping with their impairment early in life by developing habits and motion patterns that can be quite different from able-bodied individuals. Persons who have experienced lower-limb amputation as an adult, however, are faced with the task of modifying and adapting their established habits and motion patterns in order to cope with their acquired impairment. This adaptation taxes both mental and physical resources, and is, therefore, generally more successful in younger, healthier, and physically more active persons $[9,10]$.

Defining rehabilitation goals and selecting appropriate interventions requires careful consideration of a person's capabilities, functional demands, and goals. Ideally, the 
function level prior to the amputation would be restored. However, it is not always simple to define the appropriate point in time prior to surgery at which to allocate that baseline. Depending on the diagnosis, a patient may have been immobile for many years before eventually requiring limb amputation, which can be the case in persons with joint degeneration and vascular problems [11, 12]. A prosthetic limb may then help to restore a level of function that exceeds the immediate pre-operative level of function. On the other hand, it is possible that the severity of the limb loss, e.g., level and number of amputations, prohibit a rehabilitation goal that is oriented on the pre-surgery status. This is often the case in traumatic amputations $[13,14]$.

Prosthetics are a necessity if the rehabilitation goal is restoration of locomotor abilities to some extent. If prosthetics are not indicated because of the severity of the limb loss and/or reduced capabilities of the person, wheeled mobility aids are prescribed $[15 \bullet \cdot, 16]$. In many cases, both prosthetics and wheeled mobility aids are used to complement each other in different situations and activities of daily life. This paper reviews recent findings and developments in the fields of mobility training, wheelchair equipment and skills, prosthetic componentry and fitting, as well as advanced assessment tools for the rehabilitation of lower-limb amputees.

\section{Mobility Training}

A predominant concern of many amputees and a detriment to prosthetic mobility is the loss of limb stability and control [17-19]. Users of lower-limb prosthetics experience an increased risk of stumbling and falling that is associated with the level of amputation, age, and the severity of comorbidities, such as vision or hearing loss, joint contractures, impaired sensitivity, and muscle atrophies [20-23].

Exercises to increase the voluntary control of the prosthetic limb as well as the stability of standing and walking are essential components of mobility training [24-26]. With increased perceived safety grows the confidence in the prosthesis and thus the likelihood of fully utilizing the functions of the artificial limb [27, 28]. Particularly in postoperative rehabilitation, when convalescents have not yet accumulated much prosthesis experience, it is important to balance the safety and dynamic characteristics of a prosthesis-that are generally on opposing sides of the same equation-in correspondence to the successively changing capabilities of the user.

Individuals with lower-limb amputation must learn about the expected behavior of their new artificial limb that is inevitably different from the previously known behavior of their original limb. The lost function of muscles and joints, as well as afferent nerves cannot be adequately replaced, thus necessitating compensatory strategies and limitations. In terms of stability, a prosthesis that includes a foot/ankle component, e.g., any leg prosthesis for amputations proximal to the level of the (partial) foot, requires the user's CoG to be in a comparably small area vertically of the foot during stance phase. Any static or dynamic load that deviates from that area (and that would be effortlessly accommodated with some slight corrections of ankle angle in a sound leg) cannot be accommodated by the prosthetic ankle joint due the lack of muscular control. For example, during initial ground contact in a prosthetic step, when the foot is placed in front of the body's center of gravity, the resulting plantar-flexing moment may-depending on the components used to construct the prosthetic limb-either cause the prosthetic foot to (passively) deform in the sense of plantar-flexion, or translate into a knee flexing moment at the proximal end of the shank segment. The first is a safer option but comes at the expense of dynamic efficiency, as the impact energy during initial ground contact is not used to propel the body forward but is lost in the elastic deformation of the compliant foot. Similar considerations are made in the question of prosthetic knee joint selection, where again a range of options exist that emphasize one feature of able-bodied gait or another. It requires experience to utilize the respective prosthetic components in the intended fashion and to understand the fall risks in different situations.

A secondary objective of mobility training, after ensuring static and dynamic stability, is to reduce the burden of walking with a prosthetic limb. Generally, users of lowerlimb prostheses expend more metabolic energy than ablebodied controls in walking and other activities of daily life $[29,30,31 \bullet]$. They are also more susceptible to acute or chronic degeneration of their bodily structure, such as joints in the residual limb, the contralateral limb, or the spine [3235, 36*0]. Therapeutic training can help reduce these undesirable effects by emphasizing the importance of symmetrical motion patterns. Symmetrical gait is believed to be least taxing in terms of energy consumption and overuse wear [37-39]. However, it has been debated that some degree of asymmetry is more functional, given that the physical condition after amputation is signified by considerable asymmetry [40, 41].

In addition, rehabilitation goals of lower priority that may nonetheless be of increased importance for individual users of prostheses include factors such as cosmetic inconspicuousness of prosthesis use and the ability to perform certain vocational or leisurely activities [42-44].

Initial prosthetic fitting is an iterative process, corresponding with the physical and psychological changes of the convalescent. In the same sense, the strategy for mobility training must be adapted over the course of the 
rehabilitation regimen. Parameters that tend to change over time are for instance the condition of the residual limb muscles and skin.

Immediately after surgery, sutures cannot be subjected to high stresses or loads $[45,46]$. There is swelling of some extent and often a great amount of pain. In this phase, it was long assumed that the best course of action was bed rest to allow the healing process to take its course [47-49]. However, the idea of reducing the recommended time span until early prosthetic fitting has become more popular [50, 51] and has led to the practice of IPOP (immediate postoperative prosthesis) prescription. These prostheses are designed to be swiftly fitted to a residual limb that still has limited tolerance to contact pressure and is still changing in volume and shape. Their main purpose is to allow the patient to leave the bed even if for short periods of time, thereby reducing considerably the comorbidities that are secondary to prolonged bed rest, such as decubiti, thrombosis, muscle atrophies, but also depression and fatigue [52-54]. It is also believed, that early verticalization helps patients in their subsequent stages of prosthesis training, by preparing body and mind for the challenges ahead $[9,55]$.

As wound healing progresses and the residual limb approaches its eventual volume, customized sockets are fitted, usually in a sequence of several check-sockets for temporary use. Ideally, during this time there is also an opportunity to try out different prosthetic componentry options. As mentioned before, a compliant foot might be the option of choice in the early stages as it facilitates a more stable ground contact. Later on, when priorities change, the same user may be better served with an Energy Storage and Return (ESAR) foot [56, 57]. Electronically controlled or even powered components [58-60] are often only prescribed after trials with conventional parts have confirmed a respective indication. The main reasons for that are certainly of economic nature, but it may also be helpful to have experienced different prosthetic technologies in order to utilize all the benefits of the latest high-tech feet and knees and to be prepared for possible emergencies, e.g., malfunctions or empty batteries.

Prosthetic knees support a range of functionalities, differing widely between models [61, 62]. Important for the successful mobility training is, therefore, the understanding and practicing of the, respectively, prescribed knee system. Polycentric knees have stance safety built in by interconnected multiple axes, which in extension effectively moves the instantaneous center of rotation of the system outside of the actual joint structure, much like is the case in a human knee [63]. In any other but the extended position, there is no resistance to the flexion motion, which helps with the swing phase of the step. Users of such knee systems have learned to only apply their body weight on the prosthesis when the knee is fully extended. If they are subsequently fitted with a stance phase controlled hydraulic knee, they need to abandon that concept [64]. The advantage of such a knee, using for instance the SNS (swing ' $n$ stance) hydraulic unit, is that it can be adjusted to provide a flexion resistance in the stance phase, which allows a more natural and comfortable gait especially on downward slopes and stairs. Training is required to overcome the previously valid fear of falling when the knee starts buckling and to control the new prosthesis reliably.

Even after a prosthesis user is well versed in the use of their artificial limbs, it may be recommendable to monitor the gait pattern at regular intervals [65]. Gait asymmetries and relief postures can become habitual and progressive and should be rectified as possible by continued instruction and training.

\section{Wheelchair Equipment and Skills}

The more proximal the level of amputation $[16,66]$ and the more severe the impairment due to age [67] or comorbidities [68] in a given individual is, the greater the benefit of supplemental wheelchair usage [69]. This may be best illustrated by the following clinical example.

A 35-year-old young male with amputation of both legs above the knees saw the need to supplement the mobility with his prosthetic legs, which he felt were limiting his functional ambulation to fulfill his role as a full-time employed civil engineer, husband, and father. He needed to be able to maneuver over uneven recreational outdoor terrain such as playgrounds, sports fields, family theme parks, and rougher terrain at construction sites [70,71]. Therefore, he wished to explore usage of a manual wheelchair in conjunction with his prosthetic limbs. He was not interested in a power wheelchair, as he preferred active self-propulsion of a manual wheelchair, and a power wheelchair would also limit his transportation and vehicle options needed for his work. He decided that an ultralight manual wheelchair equipped with durable lightweight carbon-fiber wheels and quick release axles would work best for him, as he would have to transfer in and out of his car multiple times; the lighter the components that he would have to manipulate, the less strain on his upper extremities [72, 73]. The wheels were equipped with ergonomic hand-rims designed to reduce the risk of repetitive strain injury to wrist joints and protect the hand from injuries and lacerations [74, 75]. He was provided with wheelchair mobility training to become familiar with sensing the center of gravity (CoG) and its effect on the chair's responsiveness and stability. This was important as his CoG would be different when using the chair with and without his prosthetic legs. Instead of recommending an "amputee axel plate" that would allow the rear wheels to be set further back to increase chair stability, 
yet in turn, would shift the weight onto the casters and thereby compromising maneuverability as well as significantly increased risk for repetitive strain injuries to the upper extremity joints during harmful upper biomechanics during active self-propulsion [72, 76-78], he chose a solid backrest with multiple back-to-seat angle adjustments. The backrest support worked very well, as he could use a $90-100^{\circ}$ back-to-seat angle when wearing his prosthetic legs and "crunch" the back-to-seat angle to $85^{\circ}$, when using his wheelchair without the legs, reminding him to keep his shoulder slightly forward to prevent his chair from tipping backward [79*0]. The adjustable features and light weight components of the ultralight manual wheelchair provided him with an ideal supplemental mobility device option to let him accomplish the high-energy consuming activities for raising his young son and for field work use at construction sites.

\section{Prosthetic Components and Fitting}

Several 100 prosthetic feet and prosthetic knee models are estimated to be available in the market today, a circumstance that illustrates the perpetual efforts of the orthopedic industry to provide ever more sophisticated and innovative solutions for the prosthetic fitting of people with amputations. The catalog of one manufacturer alone lists a portfolio of 30 foot and 35 knee models [80, 81]. Most interesting among the recent developments are probably powered foot/ankle units and similarly powered knee units that strive to replace lost muscle function $[31 \cdot, 82,83]$. Active motion is not provided with more conventional microprocessor-controlled knee systems that, however, facilitate safe and energy-efficient ambulation by automatically adjusting flexion and extension resistances most accurately to the, at any given point in time, required values $[84,85]$. Other approaches of improving technology have consisted of reducing weight and complexity $[43,86]$, enhancing adaptability [87, 88], and optimizing biomechanical properties of passive prosthetic knees and feet [89, 90].

Socket-fitting options have by trend increased in number since the introduction of silicon liner-based suspension in the 1980s [91] which marked the first big paradigm shift in socket fitting. The previously used approach of suspending (trans-tibial) prostheses by epicondylar containment, thigh cuffs, or derivations thereof has continually lost importance in the subsequent decades. Today, most trans-tibial prostheses are equipped with a liner suspension system of some kind [92] and it is likely that this trend will persist, given the noted advantages over traditional approaches to include reliable suspension, ease of donning and doffing, and applicability even for unfavorable residual limb shapes
[91]. The concept of elevated vacuum suspension that has proven beneficial on a number of accounts [93-95] has contributed to the superiority of liner suspension.

In trans-femoral prosthetics, liner suspensions are only slowly becoming more prevalent, which is owed to the less readily accommodated properties of typical residual limbs, namely their length, shape, and tissue composition [96]. Nonetheless, remarkable improvements in terms of socket compliance, hip range of motion, appearance (damage to clothing), and muscle utilization have been achieved with modern socket designs and materials [97-100].

A different approach, that eliminates the need for a socket entirely, is available with the method of osseointegration [101-103]. Here, the prosthesis is attached directly to the bone via a titanium fixture, inserted to the bone and connected to an abutment which penetrates the skin. Despite some remarkable early results, the inevitable contraindications and complications of the procedure have so far prevented wide-spread use in the US. Even less prevalent is the procedure of allotransplantation of lower limbs that aims at a full restoration of the pre-amputation status, albeit at the expense of possibly severe complications [104].

\section{Advanced Tools}

Recent advances in motion and gait analysis have benefited the practice of assessing and optimizing prosthetic care in research and clinic.

The simplest form of a gait analysis is an observational analysis conducted by a clinician. For example, the test person ambulates up and down a hallway and is evaluated. While simple, a qualified clinician with extensive training and experience is necessary to identify gait deviations. Observational analyses are also limited due to the inability to simultaneously evaluate motion at different joints (e.g., hips, knee, and ankle) and planes of motion (sagittal, coronal, and transverse). Conventional gait analysis is conducted in a laboratory and uses a motion capture system to simultaneously measure Ground reaction forces (GRFs), joint kinematics, joint kinetics, and muscle activation. GRFs are measured with force platforms embedded in the laboratory floor or with a treadmill. Joint kinematics and kinetics are measured using multiple synchronized cameras to record positions of markers placed on anatomical landmarks of the test participant, combined with force plate data. Marker positions and GRFs are used with anthropometric measures and biomechanical models to obtain joint kinematics and kinetics. Muscle activations are measured with electromyography using surface or indwelling electrodes. Gait is measured as a test person walks through the motion capture space. Multiple trials may be required to 
ensure people accurately step on the force platform without altering their gait to target the force platforms. After multiple gait cycles are recorded, data are processed and analyzed off-line and a report is generated.

In recent decades, force platforms have been embedded in treadmills to allow GRFs to be collected continuously during consecutive gait cycles. Most treadmills used for gait analyses have two belts with a force platform under each belt, called dual-belt or split-belt instrumented treadmills. The dual-belt system allows each limb to be evaluated independently, medial-lateral GRFs to be measured, and belts to be controlled independently or together. Numerous studies have compared overground and treadmill gait resulting in altered kinematics [105, 106], kinetics [105, 107], and energy costs [108, 109]. Causes of these differences are speculated to be multifactorial, including altered visual feedback $[110,111]$. Treadmill walking lacks the relative motion between an observer and the environment (optic flow), thus altering visual feedback [110, 111].

Novel technologies such as the computer-assisted rehabilitation environment (CAREN) provide optic flow during treadmill walking which has resulted in temporal-spatial parameters and joint kinematics similar to overground walking [112, 113]. The CAREN system (Fig. 1; Motek Medical, Amsterdam, Netherlands) is a virtual reality environment combined with an optoelectronic motion analysis system and motion base. Virtual reality provides a computer simulation of a real-world environment that is experienced by the user through a human-machine interface [114]. Test persons are immersed into the virtual environment via surround sound and images projected on one of the three available options: a flat screen, $180^{\circ}$ cylindrical screen, or $360^{\circ}$ dome enclosure. The motion analysis system allows real-time tracking of person's motion and GRFs throughout the gait analysis. The motion base is $6^{\circ}$ of freedom platform controlled with hydraulic actuators and is embedded with a dual-belt instrumented treadmill. D-flow software (Motek Medical) provides realtime data streaming and control of these systems. Test participants are immersed in this real-time feedback loop where their motions and behaviors are considered inputs. Output devices return motor-sensory, visual, and auditory feedback to the participant. For example, joint kinetics can be measured. Outputs include real-time visual feedback of joint kinetics, physical movement of the motion base, visual movement of a projected cursor, and auditory feedback. Physical and visual perturbations can also be applied to the person to simulate environmental conditions during clinically important events. For example, a trip can be simulated with a unilateral treadmill belt acceleration or deceleration applied at specific gait events (heel strike, mid-stance, toe-off, etc.) [115]. Biomechanical gait analyses and training using the CAREN system have benefitted lower-limb amputees with demonstrated clinical improvements in pelvis and hip kinematics [116], reduced oxygen consumption [116], and improved vertical GRF symmetry [117].

Mobile gait analysis methods have been proposed to overcome some of the limitations of conventional approaches, namely the limitations on capture volumes and environments. While virtual reality systems, as described above, provide a most versatile and accurate technical approach to that end, their use is limited to large research laboratories as they are prohibitively expensive for smaller scale clinical applications. Wearable electronics, however, are more accessible and have been adapted for prosthetic gait analysis.

The option of easily inserting measurement equipment directly into the weight bearing structure of the limb is unique to prosthetics gait analysis. This poses a considerable advantage over able-bodied gait analysis methods, as most forces and moments of interest can be recorded directly where they occur and do not have to be derived from force plate and motion analysis data using a set of more or less valid assumptions [118, 119]. It should be noted that such direct measurements have also been conducted in non-amputee subjects, which, however, required the development of implantable wireless sensors to be inserted in the body as a part of endo-prostheses [120, 121].

Researchers have long utilized specially prepared load cells in experimental prostheses studies [122, 123], and the advent of microprocessor-controlled prosthetic components about 20 years ago has brought about the inclusion of sensor technology in commercially available products. But only in recent years have stand-alone sensor units been marketed with the primary purpose of collecting gait data for interpretation by a clinician or researcher, rather than by an integrated microprocessor (Fig. 2). There is yet a limited amount of published research that investigated or utilized the capabilities of such products, but early findings suggest that they are useful for a range of applications [124].

Interpretation of load cell-based gait data has proven somewhat challenging, which is mostly owed to the unilateral nature of the available information. Since only kinematics from the prosthetic leg is recorded, many popular outcome variables-most notably bilateral symmetry-cannot be computed. It is, therefore, necessary to define unilateral variables that can be used as predictor of prosthetic performance. Various approaches have been proposed, including the use of force-moment curves [125], GRF segments by step cycle compartment [126], peak forces during stair gait [127], and step-by-step variability [128]. The limitation was circumvented entirely in a study on gait symmetry in persons with bilateral trans-tibial amputation [129]. 

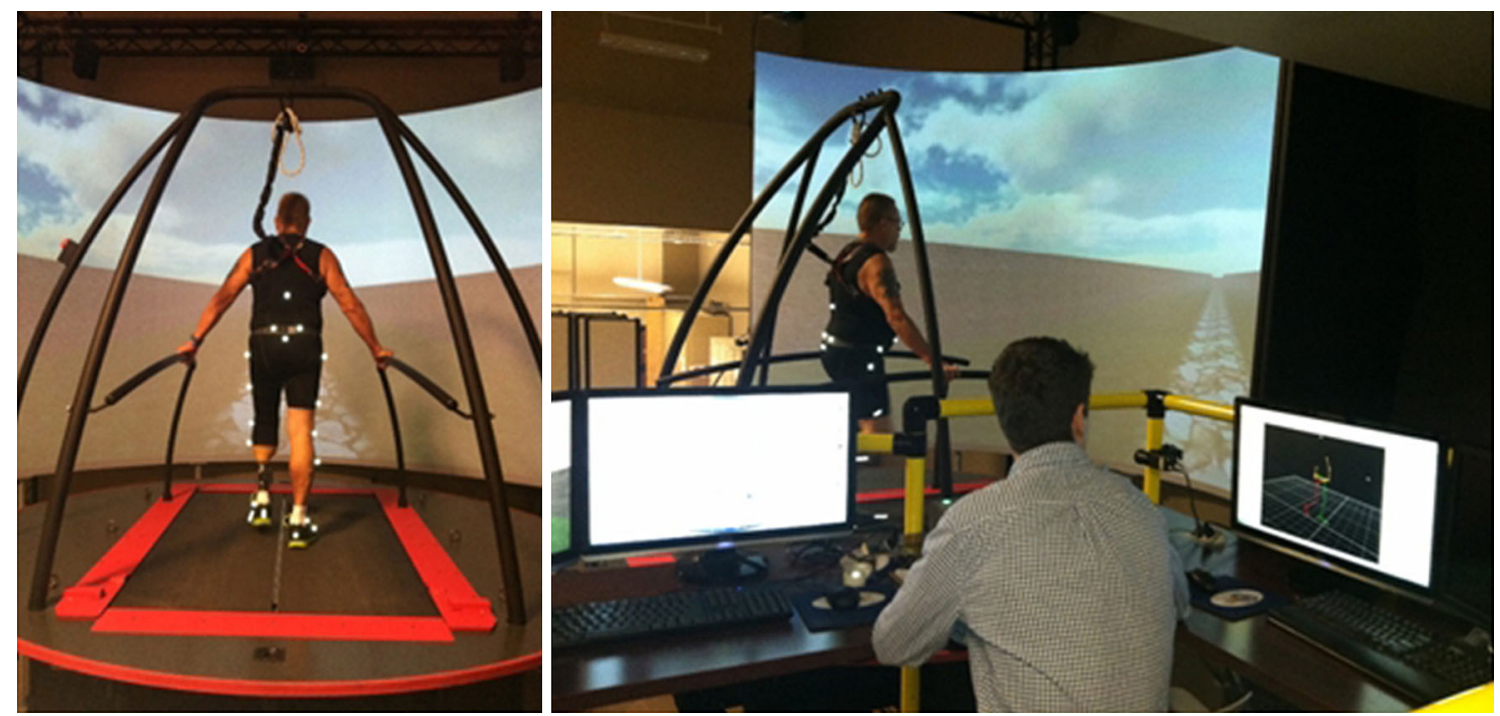

Fig. 1 Gait analysis of a lower-limb amputee using the CAREN extended system at the VA Human Engineering Research Laboratory in Pittsburgh, PA

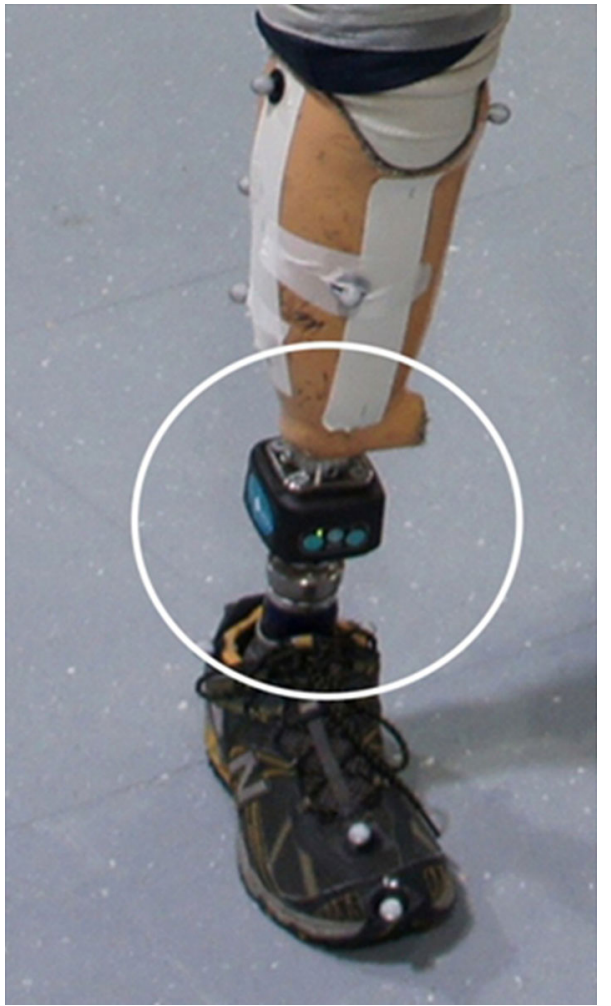

Fig. 2 Load cell for temporary inclusion in the prosthesis structure (here iPecs mobile gait lab, RTC Electronics, Ann Arbor, MI)

In clinical applications, mobile sensors have primarily been used for activity assessment purposes. The Galileo system (Orthocare, Tacoma, WA) is discussed as an accurate and reliable tool for the definition of K-levels in lower-limb prosthetics users [130]. Load cell data supported methods of prosthesis alignment optimization [126,
131] are still of restricted practical utility and will have to be further investigated to improve their accuracy and adaptability.

\section{Conclusions}

Rehabilitation of persons with lower-limb loss after amputation is an endeavor that has benefitted greatly from technological advances over the last decades. Major improvements have become possible by modern prosthetic componentry, wheelchair design, therapy regimens, and outcome assessment methods. At the same time, it must be acknowledged that rehabilitation efforts often still fall short of the ideal of restoring a functional level identical to the one from before the amputation surgery. Many persons with lower-limb amputations are still limited in their mobility and not fully satisfied with their artificial limbs or wheeled mobility solutions. Continued efforts are, therefore, indicated to further improve rehabilitation care and community reintegration for persons with lower-limb amputations.

Acknowledgments This work was supported with funds and efforts from the Department of Rehabilitation Science and Technology at the University of Pittsburgh.

\section{Compliance with Ethics Guidelines}

Conflict of Interest G. Fiedler, J. Akins, R. Cooper, S. Munoz, and R.A. Cooper all declare no conflicts of interest.

Human and Animal Rights and Informed Consent This article does not contain any studies with human or animal subjects performed by any of the authors. 


\section{References}

Papers of particular interest, published recently, have been highlighted as:

- Of importance

- Of major importance

1. Ziegler-Graham K, MacKenzie E, Ephraim P, Travison T, Brookmeyer R. Estimating the prevalence of limb loss in the United States: 2005 to 2050. Arch Phys Med Rehabil. 2008;89(3):422-9.

2. Rijnders L, Boonstra A, Groothoff J, Cornel M, Eisma W. Lower limb deficient children in the Netherlands: epidemiological aspects. Prosthet Orthot Int. 2000;24(1):13-8.

3. Vasluian E, van der Sluis CK, van Essen AJ, Bergman JE, Dijkstra PU, Reinders-Messelink HA, et al. Birth prevalence for congenital limb defects in the northern Netherlands: a 30-year population-based study. BMC Musculoskelet Disord. 2013;14(1):323.

4. Holman N, Young R, Jeffcoate W. Variation in the recorded incidence of amputation of the lower limb in England. Diabetologia. 2012;55(7):1919-25.

5. Fortington LV, Rommers GM, Postema K, van Netten JJ, Geertzen JH, Dijkstra PU. Lower limb amputation in Northern Netherlands: unchanged incidence from 1991-1992 to 2003-2004. Prosthet Orthot Int. 2013;37(4):305-10.

6. Baser O, Verpillat P, Gabriel S, Wang L. Prevalence, incidence, and outcomes of critical limb ischemia in the US Medicare population. Vasc Dis Manag. 2013;10(2):E26-36.

7. Moxey P, Gogalniceanu P, Hinchliffe R, Loftus I, Jones K, Thompson M, et al. Lower extremity amputations-a review of global variability in incidence. Diabet Med. 2011;28(10):1144-53.

8. Smith DG, Michael JW, Bowker JH. "Amputee Gait." Atlas of amputations and limb deficiencies: surgical, prosthetic, and rehabilitation principles. Rosemont: American academy of orthopaedic surgeons; 2004.

9. Sansam K, Neumann V, O'Connor R, Bhakta B. Predicting walking ability following lower limb amputation: a systematic review of the literature. J Rehabil Med. 2009;41(8):593-603.

10. Munin MC, Espejo-De Guzman MC, Boninger ML, Fitzgerald SG, Penrod LE, Singh J. Predictive factors for successful early prosthetic ambulation among lower-limb amputees. J Rehabil Res Dev. 2001;38(4):379-84.

11. Norvell DC, Turner AP, Williams RM, Hakimi KN, Czerniecki JM. Defining successful mobility after lower extremity amputation for complications of peripheral vascular disease and diabetes. J Vasc Surg. 2011;54(2):412-9.

12. Czerniecki JM, Turner AP, Williams RM, Hakimi KN, Norvell DC. Mobility changes in individuals with dysvascular amputation from the presurgical period to 12 months postamputation. Arch Phys Med Rehabil. 2012;93(10):1766-73.

13. Perkins Z, De'Ath H, Sharp G, Tai N. Factors affecting outcome after traumatic limb amputation. Br J Surg. 2012;99(S1):75-86.

14. Penn-Barwell JG. Outcomes in lower limb amputation following trauma: a systematic review and meta-analysis. Injury. 2011;42(12):1474-9.

15. •- Laferrier JZ, McFarland LV, Boninger ML, Cooper RA, Reiber GE. Wheeled mobility: factors influencing mobility and assistive technology in veterans and servicemembers with major traumatic limb loss from Vietnam war and OIF/OEF conflicts. J Rehabil Res Dev. 2010;47(4):349-60. This study shows that a notable percentage of veterans with lower extremity amputations enhance their mobility by combining the usage of both a wheelchair and ambulation with the prosthetic device.
16. Karmarkar AM, Collins DM, Wichman T, Franklin A, Fitzgerald SG, Dicianno BE, et al. Prosthesis and wheelchair use in veterans with lower-limb amputation. J Rehabil Res Dev. 2009;46(5):567-76.

17. Schaffalitzky E, Gallagher P, Maclachlan M, Ryall N. Understanding the benefits of prosthetic prescription: exploring the experiences of practitioners and lower limb prosthetic users. Disabil Rehabil. 2011;33(15-16):1314-23.

18. Legro M, Reiber G, del Aguila M, Ajax M, Boone D, Larsen J, et al. Issues of importance reported by persons with lower limb amputations and prostheses. J Rehabil Res Dev. 1999;36(3):155-63.

19. Miller WC, Speechley M, Deathe AB. Balance confidence among people with lower-limb amputations. Phys Ther. 2002;82(9):856-65.

20. Raya MA, Gailey RS, Fiebert IM, Roach KE. Impairment variables predicting activity limitation in individuals with lower limb amputation. Prosthet Orthot Int. 2010;34(1):73-84.

21. Miller WC, Speechley M, Deathe B. The prevalence and risk factors of falling and fear of falling among lower extremity amputees. Arch Phys Med Rehabil. 2001;82(8):1031-7.

22. Taylor SM, Kalbaugh CA, Blackhurst DW, Hamontree SE, Cull DL, Messich HS, et al. Preoperative clinical factors predict postoperative functional outcomes after major lower limb amputation: an analysis of 553 consecutive patients. J Vasc Surg. 2005;42(2):227-34.

23. Pauley T, Devlin M, Heslin K. Falls sustained during inpatient rehabilitation after lower limb amputation: prevalence and predictors. Am J Phys Med Rehabil. 2006;85(6):521-32.

24. Rau B, Bonvin F, De Bie R. Short-term effect of physiotherapy rehabilitation on functional performance of lower limb amputees. Prosthet Orthot Int. 2007;31(3):258-70.

25. Esquenazi A, DiGiacomo R. Rehabilitation after amputation. J Am Podiatr Med Assoc. 2001;91(1):13-22.

26. Matjacic Z, Burger H. Dynamic balance training during standing in people with trans-tibial amputation: a pilot study. Prosthet Orthot Int. 2003;27(3):214-20.

27. Kaufman K, Levine J, Brey R, Iverson B, McCrady S, Padgett $\mathrm{D}$, et al. Gait and balance of transfemoral amputees using passive mechanical and microprocessor-controlled prosthetic knees. Gait Posture. 2007;26(4):489-93.

28. Sinha R, van den Heuvel WJ, Arokiasamy P. Factors affecting quality of life in lower limb amputees. Prosthet Orthot Int. 2011;35(1):90-6.

29. Gailey R, Wenger M, Raya M, Kirk N, Erbs K, Spyropoulos P, et al. Energy expenditure of trans-tibial amputees during ambulation at self-selected pace. Prosthet Orthot Int. 1994;18(2):84-91.

30. Waters R, Perry J, Antonelli D, Hislop H. Energy cost of walking of amputees: the influence of level of amputation. J Bone Joint Surg Am. 1976;58(1):42-6.

31. - Herr HM, Grabowski AM. Bionic ankle-foot prosthesis normalizes walking gait for persons with leg amputation. Proc Roy Soc B. 2011:rspb20111194. This study demonstrates the potential of powered prosthetic devices to expand the mobility of lower limb prosthetic device users. This provides some insight to what may be the norm in the future.

32. Morgenroth DC, Segal AD, Zelik KE, Czerniecki JM, Klute GK, Adamczyk PG, et al. The effect of prosthetic foot push-off on mechanical loading associated with knee osteoarthritis in lower extremity amputees. Gait Posture. 2011;34(4):502-7.

33. Lloyd CH, Stanhope SJ, Davis IS, Royer TD. Strength asymmetry and osteoarthritis risk factors in unilateral trans-tibial, amputee gait. Gait Posture. 2010;32(3):296-300.

34. Struyf PA, van Heugten CM, Hitters MW, Smeets RJ. The prevalence of osteoarthritis of the intact hip and knee among 
traumatic leg amputees. Arch Phys Med Rehabil. 2009;90(3): $440-6$.

35. Devan H, Carman AB, Hendrick PA, Ribeiro DC, Hale LA. Perceptions of low back pain in people with lower limb amputation: a focus group study. Disabil Rehabil. 2014. doi:10.3109/ 09638288.2014 .946158$.

36. •• Gailey R, Allen K, Castles J, Kucharik J, Roeder M. Review of secondary physical conditions associated with lower-limb amputation and long-term prosthesis use. J Rehabil Res Dev. 2008;45(1):15. This is an essential review of the complications that occur when living with an amputation long-term.

37. Mattes SJ, Martin PE, Royer TD. Walking symmetry and energy cost in persons with unilateral transtibial amputations: matching prosthetic and intact limb inertial properties. Arch Phys Med Rehabil. 2000;81(5):561-8.

38. Hannah R, Morrison J, Chapman A. Prostheses alignment: effect on gait of persons with below-knee amputations. Arch Phys Med Rehabil. 1984;65(4):159-62.

39. Chow DH, Holmes AD, Lee CK, Sin S. The effect of prosthesis alignment on the symmetry of gait in subjects with unilateral transtibial amputation. Prosthet Orthot Int. 2006;30(2):114-28.

40. Rice J, Seeley MK. An investigation of lower-extremity functional asymmetry for non-preferred able-bodied walking speeds. Int J Exerc Sci. 2010;3(4):4.

41. Taylor MJ, Strike S, Dabnichki P. Turning bias and lateral dominance in a sample of able-bodied and amputee participants. Laterality. 2007;12(1):50-63.

42. Murray CD, Fox J. Body image and prosthesis satisfaction in the lower limb amputee. Disabil Rehabil. 2002;24(17):925-31.

43. Nolan L. Carbon fibre prostheses and running in amputees: a review. Foot Ankle Surg. 2008;14(3):125-9.

44. Day H. Amputee rehabilitation-finding the niche. Prosthet Orthot Int. 1998;22(2):92-101.

45. Nawijn S, Van Der Linde H, Emmelot C, Hofstad C. Stump management after trans-tibial amputation: a systematic review. Prosthet Orthot Int. 2005;29(1):13-26.

46. Mooney V, Harvey JP, McBRIDE E, Snelson R. Comparison of postoperative stump management: plaster vs. soft dressings. J Bone Joint Surg Am. 1971;53(2):241-9.

47. Smith DG, McFarland LV, Sangeorzan BJ, Reiber GE, Czerniecki JM. Postoperative dressing and management strategies for transtibial amputations: a critical review. J Rehabil Res Dev. 2003;40(3):213-24

48. Choudhury SR, Reiber GE, Pecoraro JA, Czerniecki JM, Smith DG, Sangeorzan BJ. Postoperative management of transtibial amputations in VA hospitals. J Rehabil Res Dev. 2001;38(3):293-8.

49. Horne G, Abramowicz J. The management of healing problems in the dysvascular amputee. Prosthet Orthot Int. 1982;6(1): $38-40$.

50. Vigier S, Casillas J-M, Dulieu V, Rouhier-Marcer I, D'Athis P, Didier J-P. Healing of open stump wounds after vascular below-knee amputation: plaster cast socket with silicone sleeve versus elastic compression. Arch Phys Med Rehabil. 1999;80(10):1327-30.

51. Van Velzen A, Nederhand M, Emmelot C, Ijzerman M. Early treatment of trans-tibial amputees: retrospective analysis of early fitting and elastic bandaging. Prosthet Orthot Int. 2005; 29(1):3-12.

52. Winkelman C. Bed rest in health and critical illness: a body systems approach. AACN Adv Crit Care. 2009;20(3):254-66.

53. Brower RG. Consequences of bed rest. Crit Care Med. 2009; 37(10):S422-8.

54. Jones C. Surviving the intensive care: residual physical, cognitive, and emotional dysfunction. Thorac Surg Clin. 2012;22(4): 509-16.
55. Singh R, Hunter J, Philip A. The rapid resolution of depression and anxiety symptoms after lower limb amputation. Clin rehabil. 2007;21(8):754-9.

56. Versluys R, Beyl P, Van Damme M, Desomer A, Van Ham R, Lefeber D. Prosthetic feet: state-of-the-art review and the importance of mimicking human ankle-foot biomechanics. Disabil Rehabil. 2009;4(2):65-75.

57. Hafner BJ. Clinical prescription and use of prosthetic foot and ankle mechanisms: a review of the literature. J Prosthet Orthot. 2005;17(4):S5-11.

58. Au SK, Weber J, Herr H. Powered Ankle-foot prosthesis improves walking metabolic economy. IEEE Trans Robotics. 2009;25(1):51-66.

59. Sup F, Bohara A, Goldfarb M, editors. Design and control of a powered knee and ankle prosthesis. Robotics and Automation, 2007 IEEE International Conference on; 2007: IEEE.

60. Torrealba RR, Fernández-López G, Grieco JC. Towards the development of knee prostheses: review of current researches. Kybernetes. 2008;37(9/10):1561-76.

61. Johansson JL, Sherrill DM, Riley PO, Bonato P, Herr H. A clinical comparison of variable-damping and mechanically passive prosthetic knee devices. Am J Phys Med Rehabil. 2005;84(8):563-75.

62. Hafner BJ, Willingham LL, Buell NC, Allyn KJ, Smith DG. Evaluation of function, performance, and preference as transfemoral amputees transition from mechanical to microprocessor control of the prosthetic knee. Arch Phys Med Rehabil. 2007;88(2):207-17.

63. Radcliffe C. The Knud Jansen lecture: above-knee prosthetics. Prosthet Orthot Int. 1977;1(3):146-60.

64. Michael JW. Modern prosthetic knee mechanisms. Clin Orthop Relat Res. 1999;361:39-47.

65. Baker P, Hewison S. Gait recovery pattern of unilateral lower limb amputees during rehabilitation. Prosthet Orthot Int. 1990;14(2):80-4.

66. Akarsu S, Tekin L, Safaz I, Göktepe AS, Yazıcıŏlu K. Quality of life and functionality after lower limb amputations: comparison between uni-vs. bilateral amputee patients. Prosthet Orthot Int. 2013;37(1):9-13.

67. Graham FP, Hay-Smith J. The Lived Experience of Older Adults' Adjustment to Lower Limb Amputation From the Perspective of Wheelchair Users: University of Otago; 2014.

68. Remes L, Isoaho R, Vahlberg T, Viitanen M, Rautava P. Predictors for institutionalization and prosthetic ambulation after major lower extremity amputation during an eight-year followup. Aging Clin Exp Res. 2009;21(2):129-35.

69. Cooper R. Wheelchairs: a guide to selection and configuration. New York: Demos Medical Publishers; 1998.

70. Lieberman J. Wheelchair prescription writing. Rehab clinical pocket guide. New York: Springer; 2013. p. 289-303.

71. Fitzgerald SG, Cooper R, Dicianno B, Collins D, Teodorski E, Karmarkar A et al. Impact of physical activity on participation and quality of life in individuals who use prostheses and other assistive technology/lower extremity prostheses versus wheelchair for functional performance and participation of military and veteran personnel: DTIC Document 2007.

72. Consortium for spinal cord medicine:-clinical practice guidelines for health professionals "preservation of upper limb function following spinal cord injury". paralyzed veterans of America, www.pva.org (2014). Accessed 25 Aug 2014.

73. Liu H, Pearlman J, Cooper R, Hong E-K, Wang H, Salatin B, et al. Evaluation of aluminum ultralight rigid wheelchairs versus other ultralight wheelchairs using ANSI/RESNA standards. J Rehabil Res Dev. 2010;47(5):441-55. 
74. Cooper R, Ding D, Kwarciak AM, Cooper R, Gio S, Spaeth DM, et al. Wheelchair Engineering. Hoboken: Wiley Encyclopedia of Biomedical Engineering; 2006.

75. Koontz A, Yang Y, Boninger D, Kanaly J, Cooper R, Boninger $\mathrm{M}$, et al. Investigation of the Performance of an Ergonomic Handrim as a Pain-Relieving Intervention for Manual Wheelchair Users. Assist Technol. 2006;18(2):123-45.

76. Kotajarvi BR, Sabick MB, An K-N, Zhao KD, Kaufman KR, Basford JR. The effect of seat position on wheelchair propulsion biomechanics. J Rehabil Res Dev. 2004;41(3B):403-14.

77. Cowan RE, Nash MS, Collinger JL, Koontz AM, Boninger ML. Impact of surface type, wheelchair weight, and axle position on wheelchair propulsion by novice older adults. Arch Phys Med Rehabil. 2009;90(7):1076-83.

78. Boninger M, Baldwin M, Cooper R, Koontz A, Chan L. Manual wheelchair pushrim biomechanics and axle position. Arch Phys Med Rehabil. 2000;81(5):608-13.

79. •- Pasquina PF, Cooper RA. Care of the combat amputee. Washington: Borden Institute, Office of the Surgeon General of the US Army; 2009. This is the definitive comprehensive book on lessons learned in recent military conflicts related to the treatment and care of people with traumatic amputations.

80. Ottobock. New web app: Knee Select, The practical selection aid for the right prosthetic knee joint. http://www.ottobock-group. com/en/otworld/apps/knee-select/ 2013. Accessed 25 Aug 2014.

81. US O. Lower limb prosthetics catalogue. Duderstadt 2013; 52-3.

82. Sup F, Varol HA, Goldfarb M. Upslope walking with a powered knee and ankle prosthesis: initial results with an amputee subject. IEEE Trans Neural Syst Rehabil Eng. 2011;19(1):71-8.

83. Wolf EJ, Everding VQ, Linberg AA, Czerniecki JM, Gambel C. Comparison of the power knee and c-leg during step-up and sitto-stand tasks. Gait Posture. 2013;38(3):397-402.

84. Bellmann M, Schmalz T, Ludwigs E, Blumentritt S. Immediate effects of a new microprocessor-controlled prosthetic knee joint: a comparative biomechanical evaluation. Arch Phys Med Rehabil. 2012;93(3):541-9.

85. Bellmann M, Schmalz T, Blumentritt S. Comparative biomechanical analysis of current microprocessor-controlled prosthetic knee joints. Arch Phys Med Rehabil. 2010;91(4):644-52.

86. Andrysek J. Lower-limb prosthetic technologies in the developing world: a review of literature from 1994-2010. Prosthet Orthot Int. 2010;34(4):378-98.

87. Lambrecht BG, Kazerooni H, editors. Design of a semi-active knee prosthesis. Robotics Automation, 2009. ICRA'09. IEEE International Conference on; 2009: IEEE.

88. Williams RJ, Hansen AH, Gard SA. Prosthetic ankle-foot mechanism capable of automatic adaptation to the walking surface. J Biomech Eng. 2009;131(3):035002.

89. Fey NP, Klute GK, Neptune RR. Optimization of prosthetic foot stiffness to reduce metabolic cost and intact knee loading during below-knee amputee walking: a theoretical study. J Biomech Eng. 2012;134(11):111005.

90. Hansen AH, Childress DS. Investigations of roll-over shape: implications for design, alignment, and evaluation of ankle-foot prostheses and orthoses. Disabil Rehabil. 2010;32(26):2201-9.

91. Baars E, Geertzen J. Literature review of the possible advantages of silicon liner socket use in trans-tibial prostheses. Prosthet Orthot Int. 2005;29(1):27-37.

92. Watts A. Academy Society Spotlight: Choosing a Gel Liner. Westminster: The O\&P Edge; 2014.

93. Street G. Vacuum suspension and its effects on the limb. Orthopadie Technik. 2006;4:1-7.

94. Klute GK, Berge JS, Biggs W, Pongnumkul S, Popovic Z, Curless B. Vacuum-assisted socket suspension compared with pin suspension for lower extremity amputees: effect on fit, activity, and limb volume. Arch Phys Med Rehabil. 2011;92(10):1570-5.

95. Kahle JT, Orriola JJ, Johnston W, Highsmith MJ. The effects of vacuum-assisted suspension on residual limb physiology, wound healing, and function: a systematic review. Technol Innov. 2014;15(4):333-41.

96. Kahle JT, Highsmith MJ. Transfemoral sockets with vacuumassisted suspension comparison of hip kinematics, socket position, contact pressure, and preference: ischial containment versus brimless. J Rehabil Res Dev. 2013;50(9):1241-51.

97. Traballesi M, Delussu AS, Averna T, Pellegrini R, Paradisi F, Brunelli S. Energy cost of walking in transfemoral amputees: comparison between marlo anatomical socket and ischial containment socket. Gait Posture. 2011;34(2):270-4.

98. Alley RD, Williams TW III, Albuquerque MJ, Altobelli DE. Prosthetic sockets stabilized by alternating areas of tissue compression and release. J Rehabil Res Dev. 2011;48(6): 679-96.

99. Van de Meent H, Hopman MT, Frölke JP. Walking ability and quality of life in subjects with transfemoral amputation: a comparison of osseointegration with socket prostheses. Arch Phys Med Rehabil. 2013;94(11):2174-8.

100. Guenther M, Fiedler G. The milwaukee-socket: scientific findings as the foundation of an improved general trans-femoral socket design concept. 13th ISPO World congress; Leipzig 2010.

101. Branemark R, Branemark P, Rydevik B, Myers RR. Osseointegration in skeletal reconstruction and rehabilitation: a review. J Rehabil Res Dev. 2001;38(2):175-82.

102. Sullivan J, Uden M, Robinson K, Sooriakumaran S. Rehabilitation of the trans-femoral amputee with an osseointegrated prosthesis: The United Kingdom experience. Prosthet Orthot Int. 2003;27(2):114-20.

103. Lee WC, Frossard LA, Hagberg K, Haggstrom E, Brånemark R, Evans JH, et al. Kinetics of transfemoral amputees with osseointegrated fixation performing common activities of daily living. Clin Biomech. 2007;22(6):665-73.

104. Carty MJ, Zuker R, Cavadas P, Pribaz JJ, Talbot SG, Pomahac B. The case for lower extremity allotransplantation. Plast Reconstr Surg. 2013;131(6):1272-7.

105. Riley PO, Paolini G, Della Croce U, Paylo KW, Kerrigan DC. A kinematic and kinetic comparison of overground and treadmill walking in healthy subjects. Gait Posture. 2007;26(1):17-24.

106. Strathy G, Chao E, Laughman R. Changes in knee function associated with treadmill ambulation. J Biomech. 1983;16(7): 517-22.

107. White SC, Yack HJ, Tucker CA, Lin H-Y. Comparison of vertical ground reaction forces during overground and treadmill walking. Med Sci Sports Exerc. 1998;30(10):1537-42.

108. Pearce M, Cunningham D, Donner A, Rechnitzer P, Fullerton G, Howard J. Energy cost of treadmill and floor walking at selfselected paces. Eur J Appl Physiol Occup Physiol. 1983;52(1): 115-9.

109. Traballesi M, Porcacchia P, Averna T, Brunelli S. Energy cost of walking measurements in subjects with lower limb amputations: a comparison study between floor and treadmill test. Gait Posture. 2008;27(1):70-5.

110. Arsenault AB, Winter DA, Marteniuk RG. Treadmill versus walkway locomotion in humans: an EMG study. Ergon. 1986;29(5):665-76.

111. van Ingen SG. Some fundamental aspects of the biomechanics of overground versus treadmill locomotion. Med Sci Sports Exerc. 1979;12(4):257-61.

112. Gates DH, Darter BJ, Dingwell JB, Wilken JM. Comparison of walking overground and in a Computer Assisted Rehabilitation 
Environment (CAREN) in individuals with and without transtibial amputation. J Neuroeng Rehabil. 2012;9(1):81.

113. Sheik-Nainar MA, Kaber DB. The utility of a virtual reality locomotion interface for studying gait behavior. Hum Factors. 2007;49(4):696-709.

114. Holden MK. Virtual environments for motor rehabilitation: review. Cyberpsychol Behav. 2005;8(3):187-211.

115. Sessoms PH, Wyatt M, Grabiner M, Collins J-D, Kingsbury T, Thesing N, et al. Method for evoking a trip-like response using a treadmill-based perturbation during locomotion. J Biomech. 2014;47(1):277-80.

116. Darter BJ, Wilken JM. Gait training with virtual reality-based real-time feedback: improving gait performance following transfemoral amputation. Phys Ther. 2011;91(9):1385-94.

117. Nottingham EM, Linberg AA, Wolf EJ, editors. A comparison of feedback strategies in a virtual environment to improve gait symmetry of service members with unilateral transtibial amputation. Omaha, NE: American Society of Biomechanics; 2013.

118. Koehler SR, Dhaher YY, Hansen AH. Cross-validation of a portable, six-degree-of-freedom load cell for use in lower-limb prosthetics research. J Biomech. 2014;47(6):1542-7.

119. Fiedler G, Slavens B, Briggs D, Hafner BJ. Criterion and Construct Validity of Prosthesis-Integrated Measurement of Joint Moment Data in Persons With Trans-Tibial Amputation. Journal of Applied Biomechanics. 2014;(in press). doi:10.1123/ jab.2013-0309.

120. Hodge W, Carlson K, Fijan R, Burgess R, Riley P, Harris W, et al. Contact pressures from an instrumented hip endoprosthesis. J Bone Joint Surg Am. 1989;71(9):1378-86.

121. Kotzar G, Davy D, Goldberg V, Heiple K, Berilla J, Brown R, et al. Telemeterized in vivo hip joint force data: a report on two patients after total hip surgery. J Orthop Res. 1991;9(5):621-33.

122. Sanders J, Miller R, Berglund D, Zachariah S. A modular sixdirectional force sensor for prosthetic assessment: a technical note. J Rehabil Res Dev. 1997;34(2):195-202.
123. Frossard L, Stevenson N, Smeathers J, Häggström E, Hagberg $\mathrm{K}$, Sullivan J, et al. Monitoring of the load regime applied on the osseointegrated fixation of a trans-femoral amputee: a tool for evidence-based practice. Prosthet Orthot Int. 2008;32(1):68-78.

124. Fiedler G. Prosthesis-integrated load cells as alternatives to conventional gait analysis methods - capabilities and limitations ISPO 2013, Symposium on load measurement for evidence based practice; Feb. 4; Hyderabad, India 2013.

125. Neumann ES, Brink J, Yalamanchili K, Lee JS. Use of a load cell and force-moment curves to compare transverse plane moment loads on transtibial residual limbs: a preliminary investigation. Prosthet orthot int. 2013:0309364613497048.

126. Kobayashi T, Orendurff MS, Zhang M, Boone DA. Individual responses to alignment perturbations in socket reaction moments while walking in transtibial prostheses. Clin Biomech. 2014.

127. Fiedler G, Slavens BA, Smith RO, editors. Influence of Handrail Use on Stair Walking Stability in Trans-Tibial Amputees. 1st Occupational Science Summit. MO: St. Louis; 2012.

128. Fiedler G. Amputee step variance within and between conditions of different exertion levels and alignment perturbations in a single-subject study design. OT-World; May 13-18, 2014; Leipzig 2014.

129. Fiedler G, Slavens BA, Hafner BJ, Briggs D, Smith RO. Leg laterality differences in persons with bilateral transtibial amputation: a pilot study using prosthesis-integrated load cells. J Prosthet Orthot. 2013;25(4):168-76.

130. Orendurff MS, Boone DA, Chou T, Kobayashi T. A comparison of a calculated functional level estimate and expert prosthetists' estimate of functional level based on actual ambulatory activity in transtibial amputees. Resna Annual Conference 2013.

131. Neumann ES, Brink J, Yalamanchili K, Lee JS. Use of a load cell and force-moment analysis to examine transtibial prosthesis foot rollover kinetics for anterior-posterior alignment perturbations. J Prosthet Orthot. 2012;24(4):160-74. 